\title{
A repeated strategy for dumping
}

J. Martins, N. Banik, A.A. Pinto

\begin{abstract}
In this work, we study the phenomena of dumping in a duopoly market through an infinitely repeated game. We consider two firms of different countries competing in the same country. When both firms are cooperating, if the foreign firm deviates from cooperation this can be interpreted as dumping and a period of punishment can be imposed to the foreign firm. After this, firms can play continuously the deviation-punishment game or compete à la Cournot. Previously, we observe that the repeated strategy of deviation-punishment is not adopted in the case of symmetric demand equations. Here, we observe that this strategy of repeated dumping can appear as the best repeated strategy when the demand equations are non-symmetric.
\end{abstract}

\section{Introduction}

The phenomena of dumping appear when a firm practices a price for a certain good in the foreign market lower than the price charged for the same good in the domestic market [14]. Since this can be seen as selling at less than the fair value, the dumping is assumed to be an unfair practice in international trade. This type of pricing policy is frequently associated with a deliberate action of large companies to eliminate competition in foreign markets, in order to consolidate as monopolies. Hence, this

\section{J. Martins}

LIAAD-INESC TEC; Department of Mathematics, School of Technology and Management, Polytechnic Institute of Leiria. Campus 2, Morro do Lena - Alto do Vieiro, 2411-901 Leiria, Portugal, e-mail: jgouveia.martins@gmail.com

N. Banik

Center for Advance Financial Studies, Institute for Financial Management and Research, Chennai - 600034, India. e-mail: nilbanik@gmail.com

A. Pinto

LIAAD-INESC TEC; Department of Mathematics, Faculty of Sciences, University of Porto. Rua do Campo Alegre, 687, 4169-007, Portugal, e-mail: aapinto1@gmail.com 
phenomena is highly related with companies that have a huge productive capacity. To protect the domestic industry, many governments developed anti-dumping laws to impose penalties on suspiciously low-priced imports. To govern the application of anti-dumping measures there exist the "anti-dumping agreement", created by the World Trade Organization (WTO). Te WTO aims to supervise and liberalize international trades, promoting the negotiation between members to ensure a freely and fair trade between nations.

Dumping is studied in this work as a phenomena that happens in an international trade between two nations. Hence, we consider two firms of different countries competing in quantities of a certain good at the same country [12]. The trade runs infinitely, in a discrete number of periods of a game that have three different strategies: collusion, deviation from collusion followed by punishment and Cournot. In the collusion strategy both firms cooperate in their mutual benefit and produce the quantities that maximize the joint profit. After a period of the game when both firms play collusion, the foreign firm might deviates from collusion abandoning the cooperation between both. This deviation can be understood as dumping since the price practiced by the foreign firm decreases in the period of deviation. As consequence of deviation, the foreign firm might suffer a punishment in the period after the deviation if the dumping is proved. The punishment results from a penalty imposed by the government of the home country, usually, as a tariff per unit of the good. We assume that this tariff puts the foreign firm out of the market in the punishment period and, therefore, the home firm realizes the monopoly profit in this period of the game. To impose anti-dumping duties, the home firm have to lobby its government by a certain price that will decrease its own profit in the punishment period. There are two ways in which the domestic firm can induce its government to impose a tariff. First, the domestic firm can strategically alter its behavior (trying to induce the deviation of the foreign firm) and thereby influence anti-dumping outcome in the following stage of the game (see Ethier and Fischer [5], Fischer [6], Staiger and Wolak [13] and Reitzes [11]). Second, by mounting political pressure (see Moore [9, 10], DeVault [2], and Hansen and Prusa [7, 8]). After the two periods of the game, when the foreign firm deviates from collusion and suffer the punishment, the home firm has two possible repeated strategies to adopt: allow the repetition of the strategies taken by both firms in the previous two periods, originating the repeated deviation-punishment strategy, or force a Cournot competition where the firms produce the amount of output independently of each other to maximize its own profits, originating the deviation-punishment followed by Cournot strategy. To implement this repeated game we developed an economical model in [1] and observe that the optimal strategies in the symmetric case of the model are repeated collusion and deviation-punishment followed by Cournot. Here, we consider the non-symmetric model and observe that the repeated deviation-punishment strategy should also be adopted for some parameter values. 


\section{The economic model}

We consider an international trade market constituted by a duopoly, where one firm from the home country is competing in quantities of production for a certain good with another firm from a foreign country. Let $F_{1}$ denote the home firm and $F_{2}$ the foreign firm. Let $q_{i}$ denote the produced quantities and $p_{i}$ the selling prices for firm $F_{i}, i=1,2$. We assume a quadratic utility function that origins the linear inverse demand functions $[3,4,15]$

$$
\begin{aligned}
& p_{1}=\alpha_{1}-\beta_{1} q_{1}-\gamma q_{2} \\
& p_{2}=\alpha_{2}-\gamma q_{1}-\beta_{2} q_{2}
\end{aligned}
$$

with $\alpha_{i}>0, \beta_{i}>0$ and $\beta_{1} \beta_{2} \geq \gamma^{2}$. The parameters $\alpha_{i}$ represents the maximum price that anyone would pay for the good and $\beta_{i}$ measures the negative relationship between the quantity demanded and the price. The parameter $\gamma$ measures the degree of substitutability of the goods: these can be substitutes if $\gamma>0$, independent if $\gamma=0$ or complements if $\gamma<0$. The goods are perfect substitutes when $\beta_{1}=\beta_{2}=\gamma$ and perfect complements when $\beta_{1}=\beta_{2}=-\gamma$. If $\alpha_{1}=\alpha_{2}$ and $\beta_{1}=\beta_{2}=\gamma$ the model do not distinguish the goods produced by the two firms and therefore we say that they are identical. With these notations and neglecting the marginal costs, the profit for the firm $F_{i}$ is given by

$$
\pi_{i}=p_{i} q_{i}=\left(\alpha_{i}-\beta_{i} q_{i}-\gamma q_{j}\right) q_{i}, \quad i=1,2 .
$$

\section{The dumping game}

Now, we consider an infinitely repeated game where both firms have to choose in every periods of the game the quantities of the goods that will be produced.

The first strategy that we consider is collusion. This strategy corresponds to a cooperation in mutual benefit of both firms in order to maximize the joint profit $\left(\pi_{1}+\pi_{2}\right)$. If both firms adopt a collusion strategy in every periods of the game, namely, the repeated collusion strategy $(C O L)$, the total value of the profit realized by the home firm is given by

$$
\pi_{1}^{C O L}=\frac{\alpha_{1}\left(\alpha_{1} \beta_{2}-\alpha_{2} \gamma\right)}{4\left(\beta_{1} \beta_{2}-\gamma^{2}\right)}
$$

and given by

$$
\pi_{2}^{C O L}=\frac{\alpha_{2}\left(\alpha_{2} \beta_{1}-\alpha_{1} \gamma\right)}{4\left(\beta_{1} \beta_{2}-\gamma^{2}\right)}
$$


for the foreign firm, as derived in [1]. To simplify the expressions of the profits, Eq. (3), (4) and the equations of the profits in the next repeated strategies are multiplied by the factor $(1-\delta)$, where $\delta \in(0 ; 1)$ denotes the rate of discount.

Now, we assume that, after a certain period of the game when both firms play a collusion strategy, the foreign firm deviates from collusion in order to maximize its own profit. If it is proved that this deviation is dumping, a following period of punishment can be imposed to the foreign firm. The punishment results from the home firm lobby its own government to impose a prohibitive tariff on the foreign firm during the period of punishment. After these two periods of deviation and punishment of the foreign firm, we assume that the home firm might allow the repetition of this deviation-punishment strategy, resulting in the repeated deviationpunishment strategy (DPR), or might force a Cournot competition, resulting in the Deviation-Punishment followed by a Cournot strategy (DPC). In the case of the repeated deviation-punishment strategy, it was derived in [1] that

$$
\pi_{1}^{D P R}=\frac{\left(2 \alpha_{1} \beta_{1} \beta_{2}^{2}-3 \beta_{2} \alpha_{1} \gamma^{2}+\alpha_{2} \gamma^{3}\right) \frac{\beta_{2} \alpha_{1}-\alpha_{2} \gamma}{8 \beta_{2}\left(\beta_{1} \beta_{2}-\gamma^{2}\right)^{2}}+\delta\left(\frac{\alpha_{1}^{2}}{4 \beta_{1}}-L\right)}{1+\delta}
$$

is the total value of the profit for the home firm, where $L$ is the price payed by the home firm to lobby its government. For the foreign firm, the total value of the profit is given by

$$
\pi_{2}^{D P R}=\frac{\beta_{2}}{1+\delta}\left(\frac{2 \alpha_{2} \beta_{1} \beta_{2}-\alpha_{2} \gamma^{2}-\gamma \beta_{2} \alpha_{1}}{4 \beta_{2}\left(\beta_{1} \beta_{2}-\gamma^{2}\right)}\right)^{2}
$$

In the case of both firms play a deviation-punishment strategy in the first two periods of the game and afterwards play a Cournot competition, the total profit for the home firm is given by

$$
\begin{aligned}
\pi_{1}^{D P C}= & (1-\delta)\left(\left(2 \alpha_{1} \beta_{1} \beta_{2}^{2}-3 \beta_{2} \alpha_{1} \gamma^{2}+\alpha_{2} \gamma^{3}\right) \frac{\beta_{2} \alpha_{1}-\alpha_{2} \gamma}{8 \beta_{2}\left(\beta_{1} \beta_{2}-\gamma^{2}\right)^{2}}\right. \\
& \left.+\delta\left(\frac{\alpha_{1}^{2}}{4 \beta_{1}}-L\right)\right)+\delta^{2} \beta_{1}\left(\frac{2 \alpha_{1} \beta_{2}-\gamma \alpha_{2}}{4 \beta_{1} \beta_{2}-\gamma^{2}}\right)^{2}
\end{aligned}
$$

and the total profit for the foreign firm is given by

$$
\begin{aligned}
\pi_{2}^{D P C}= & (1-\delta) \beta_{2}\left(\frac{2 \alpha_{2} \beta_{1} \beta_{2}-\alpha_{2} \gamma^{2}-\gamma \beta_{2} \alpha_{1}}{4 \beta_{2}\left(\beta_{1} \beta_{2}-\gamma^{2}\right)}\right)^{2} \\
& +\delta^{2} \beta_{2}\left(\frac{2 \alpha_{2} \beta_{1}-\gamma \alpha_{1}}{4 \beta_{1} \beta_{2}-\gamma^{2}}\right)^{2}
\end{aligned}
$$




\section{Main results and discussion}

The action of make dumping corresponds to the deviation from collusion practiced by the foreign firm. Hence, the foreign firm starts to decide between deviationpunishment strategy or maintain the collusion strategy. If the foreign firm chooses the deviation-punishment strategy, then the home firm will decide to play a repeated deviation-punishment strategy or to force a Cournot competition. To discover which strategy leads to a higher profit and therefore the best repeated strategy for both firms, we will compare the previous expressions of the profits. The case of symmetric model, parameters $\alpha_{1}=\alpha_{2}$ and $\beta_{1}=\beta_{2}$, was studied in [1] and the repeated deviation-punishment strategy never was the best repeated strategy. Now, we will show that this strategy appears as best repeated strategy for both firms if the parameter values do not make the model symmetric.

To decide between make dumping or maintain collusion, the foreign firm starts to observe what the home firm will choose to do in the periods after the deviationpunishment. If the home firm prefer repeat the deviation-punishment rather than Cournot competition and if the foreign firm prefer repeat the deviation-punishment strategy rather than collusion

$$
\pi_{2}^{D P R}>\pi_{2}^{C O L} \wedge \pi_{1}^{D P R}>\pi_{1}^{D P C}
$$

then the best repeated strategy for the game is the repeated deviation-punishment strategy $(D P R)$. To discover when this strategy should be adopted, we start to compute the values of the rate of discount $\delta$ for which $\pi_{1}^{D P R}=\pi_{1}^{D P C}$ and obtain

$$
\delta_{1}^{D P C / D P R}=\frac{\left(\gamma^{6}-8 \gamma^{5}+12 \gamma^{4}+8 \gamma^{3}+48 \gamma^{2}-128 \gamma+64\right) \gamma}{4 \gamma^{7}-96 \gamma^{5}+128 \gamma^{4}+336 \gamma^{3}-512 \gamma^{2}-320 \gamma+512} .
$$

In this result, and throughout the following results, we fix the parameters $\alpha_{1}=\alpha_{2}$ and $\beta_{2}=2 \beta_{1}=2$. We also consider that the home firm does not pay to lobby its government, hence $L=0$. For values of $\delta<\delta_{1}^{D P C / D P R}$ we observe that $\pi_{1}^{D P C}>$ $\pi_{1}^{D P R}$ and the home firm will choose the Cournot competition after the deviationpunishment periods, and for values of $\delta>\delta_{1}^{D P C / D P R}$ we observe that $\pi_{1}^{D P R}>\pi_{1}^{D P C}$ and the home firm will choose to repeat the deviation-punishment after the first two periods of deviation-punishment. These choices of the home firm are illustrated in Fig. 1 (a). Solving the equation $\pi_{2}^{D P R}=\pi_{2}^{C O L}$ for the same parameter values, we obtain the curve

$$
\delta_{2}^{D P R / C O L}=\frac{\left(\gamma^{2}-4 \gamma+4\right) \gamma^{2}}{8 \gamma^{3}-8 \gamma^{2}-16 \gamma+16}
$$

For values of $\delta<\delta_{2}^{D P R / C O L}$ we observe that $\pi_{2}^{D P R}>\pi_{2}^{C O L}$ and the foreign firm prefers the repeated deviation-punishment strategy. For values of $\delta>\delta_{2}^{D P R / C O L}$ we observe that $\pi_{2}^{C O L}>\pi_{2}^{D P R}$ and the foreign firm prefers the repeated collusion strategy, as illustrated in Fig. 1 (b). Hence, by Eq. (9), we conclude that for values of $\delta$ such that 


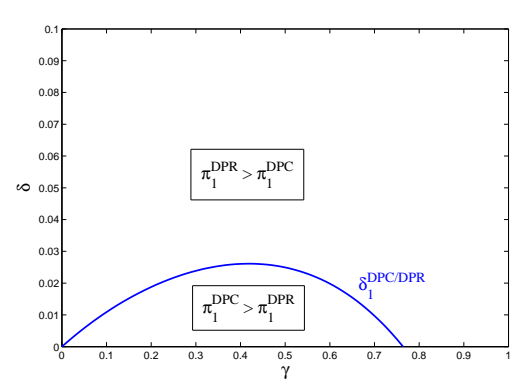

(a)

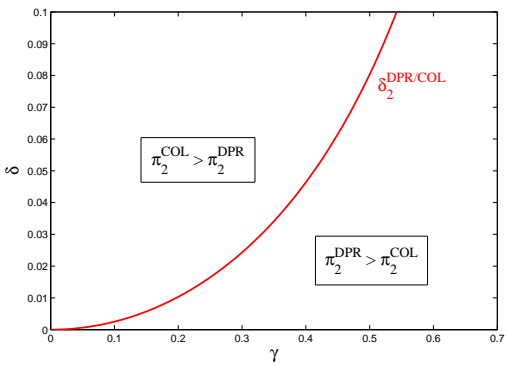

(b)

Fig. 1: The curve $\delta_{1}^{D P C / D P R}$ (left) where the profits of the home firm in the $D P C$ and $D P R$ strategies are equal. The home firm realizes a higher profit with the $D P R$ strategy above the curve and with the $D P C$ strategy below the curve. The curve $\delta_{2}^{D P R / C O L}$ (right) dividing the $(\gamma ; \delta)$ plane in the regions where the foreign firm prefers the DPR strategy and the DPC strategy. The values of the parameters used are: $\alpha_{1}=\alpha_{2}, \beta_{2}=2 \beta_{1}=2$ and $L=0$.

$$
\delta_{1}^{D P C / D P R}<\delta<\delta_{2}^{D P R / C O L}
$$

the best repeated strategy for both firms is the repeated deviation-punishment (DPR), as illustrated in Fig. 2.

Fig. 2 The $\delta_{1}^{D P C / D P R}$ curve above which the home firm prefers the DPR strategy and the $\delta_{2}^{D P R / C O L}$ curve below which the foreign firm prefers the DPR strategy. For values of $\delta$ above $\delta_{1}^{D P C / D P R}$ and below $\delta_{2}^{D P R / C O L}$ the best repeated strategy for both firms is $D P R$.

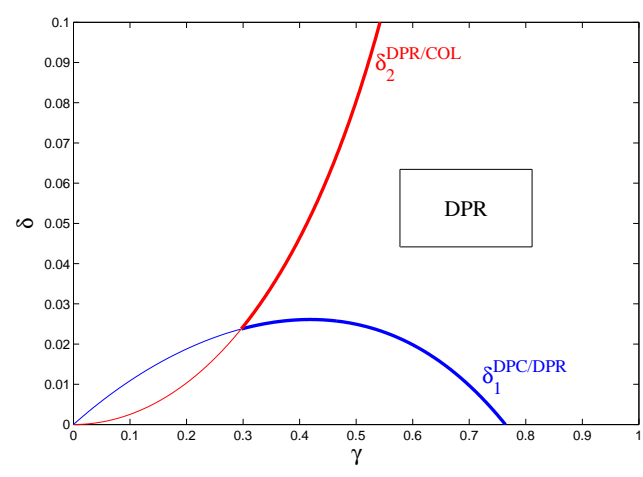

On the other hand, if the home firm will chose a Cournot competition rather than play a repeated deviation-punishment game and if the foreign firm prefer a Cournot game after the deviation-punishment periods

$$
\pi_{2}^{D P C}>\pi_{2}^{C O L} \wedge \pi_{1}^{D P C}>\pi_{1}^{D P R}
$$


then the best repeated strategy for the game is deviation-punishment followed by Cournot $(D P C)$. We start to observe that the equation $\pi_{2}^{D P C}=\pi_{2}^{C O L}$ is quadratic

$$
A_{2} \delta^{2}+A_{1} \delta+A_{0}=0
$$

with

$$
\begin{aligned}
& A_{2}=-64 \gamma^{6}+256 \gamma^{5}-1024 \gamma^{3}+768 \gamma^{2}+1024 \gamma-1024, \\
& A_{1}=\gamma^{8}+4 \gamma^{7}-20 \gamma^{6}-80 \gamma^{5}+144 \gamma^{4}+512 \gamma^{3}-512 \gamma^{2}-1024 \gamma+1024, \\
& A_{0}=-\gamma^{8}+4 \gamma^{7}+12 \gamma^{6}-64 \gamma^{5}+256 \gamma^{3}-256 \gamma^{2} .
\end{aligned}
$$

The two solutions of eq. (14) define the curve $\delta_{2}^{D P C / C O L}$ plotted in Fig. 3 (a). On the right hand side of the curve $\delta_{2}^{D P C / C O L}$ we observe that $\pi_{2}^{D P C}>\pi_{2}^{C O L}$ and the foreign firm prefers a Cournot competition after the two periods of deviation-punishment. On the left hand side of the curve $\delta_{2}^{D P C / C O L}$ we observe that $\pi_{2}^{C O L}>\pi_{2}^{D P C}$ and the foreign firm prefers the repeated collusion strategy rather than deviation-punishment followed by Cournot competition. Hence, considering the solution of Eq. (14) given by $\delta_{2}^{D P C / C O L}=\left(-A_{1}-\sqrt{A_{1}^{2}-4 A_{2} A_{0}}\right) /\left(2 A_{2}\right)$ and the $\delta_{1}^{D P C / D P R}$ curve defined in Eq. (10), by Eq. (13) we conclude that for values of $\delta$ such that

$$
\delta<\delta_{2}^{D P C / C O L} \wedge \delta<\delta_{1}^{D P C / D P R}
$$

the best repeated strategy for both firms is deviation-punishment followed by Cournot $(D P C)$, as illustrated in Fig. 3 (b).

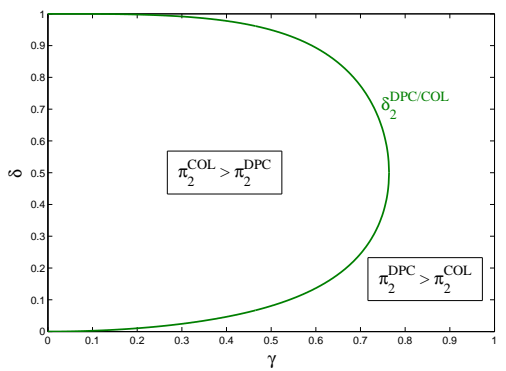

(a)

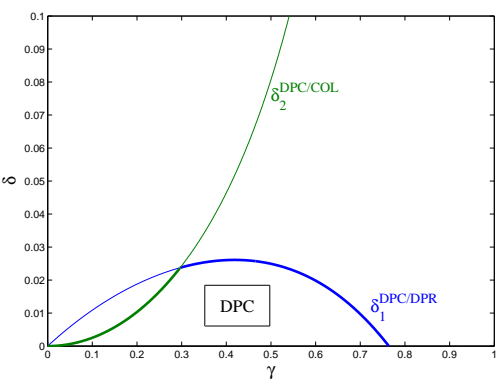

(b)

Fig. 3: The curve $\delta_{2}^{D P C / C O L}$ separating the preferable strategy for the foreign firm: on the left hand side it prefers the $C O L$ strategy and on the right hand side it prefers the $D P C$ strategy. The curves $\delta_{2}^{D P C / C O L}$ and $\delta_{1}^{D P C / D P R}$ (right) defining the parameters region where the best repeated strategy for both firms is $D P C$. 
Fig. 4 The curves $\delta_{1}^{D P C / D P R}$, $\delta_{2}^{D P R / C O L}$ and $\delta_{2}^{D P C / C O L}$ dividing the $(\gamma ; \delta)$ plane in the regions where the best repeated strategy is $C O L$, $D P C$ and $D P R$.

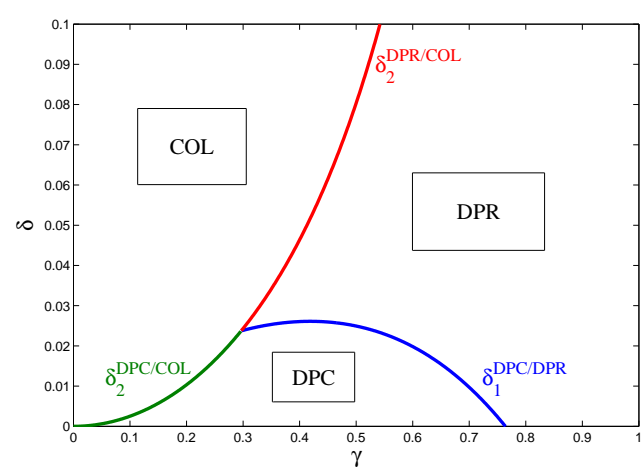

The best repeated strategy for the game is repeated collusion (COL) if, when the home firm will choose a Cournot competition, the foreign firm prefers collusion rather than Cournot, or if, when the home firm will choose a repeated deviation-punishment strategy, the foreign firm prefers collusion rather than repeated deviation-punishment

$$
\left(\pi_{T, 2}^{C O L}>\pi_{T, 2}^{D P C} \wedge \pi_{T, 1}^{D P C}>\pi_{T, 1}^{D P R}\right) \quad \vee \quad\left(\pi_{T, 2}^{C O L}>\pi_{T, 2}^{D P R} \wedge \pi_{T, 1}^{D P R}>\pi_{T, 1}^{D P C}\right) .
$$

Using the curves $\delta_{1}^{D P C / D P R}, \delta_{2}^{D P R / C O L}$ and $\delta_{2}^{D P C / C O L}$ we characterize the parameter values for which the best repeated strategy is collusion. In Fig. 4, we present this region of values in addition to the regions where the best repeated strategy is repeated deviation-punishment and deviation-punishment followed by Cournot.

For other values of the parameters $\alpha_{1}, \alpha_{2}, \beta_{1}$ and $\beta_{2}$ the curves of diagram presented in Fig. 4 are very similar. When the price payed by the home firm to lobby its own government is positive $L>0$, we observe that the $\delta_{1}^{D P C / D P R}$ curve goes up and the repeated deviation-punishment tends to disappear. This is expectable since the home firm would not be much interested to pay a positive amount to lobby its government so many times.

\section{Conclusions}

In this work we observe that the repeated deviation-punishment strategy, that can be interpreted as a repeated strategy for dumping, appears as the best repeated strategy in an international trade if we consider non-symmetric inverse demand functions, in contrast with the symmetric case. This repeated deviation-punishment strategy is more likely to be adopted by the two firms if the goods traded are highly substitutes, which is the case of high values of $\gamma$. 
Acknowledgements We thank LIAAD-INESC TEC, USP-UP project, Faculty of Sciences, University of Porto and Calouste Gulbenkian Foundation. We acknowledge the financial support received by the ERDF - European Regional Development Fund through the Operational Programme for Competitiveness and Internationalisation - COMPETE 2020 Programme within project "POCI01-0145-FEDER-006961", and by National Funds through the FCT - Fundação para a Ciência e a Tecnologia (Portuguese Foundation for Science and Technology) within project UID/EEA/50014/ 2013 and ERDF (European Regional Development Fund) through the COMPETE Program (operational program for competitiveness) and by National Funds through the FCT within Project "Dynamics, optimization and modelling", with reference PTDC/MAT-NAN/6890/2014. Alberto Pinto also acknowledges the financial support received through the Special Visiting Researcher Program (Bolsa Pesquisador Visitante Especial - PVE) "Dynamics, Games and Applications" with reference 401068/2014-5 (call: MEC/MCTI/CAPES/CNPQ/FAPS), at IMPA, Brazil. Part of this research was done during visits by the authors to IMPA (Brazil), University of São Paulo (Brazil), University of Warwick (United Kingdom), Institut Henri Poincaré (France) and SUNY (USA) who thank them for their hospitality.

\section{References}

1. Banik, N., Ferreira, F., Martins, J., Pinto, A.: An Economical Model For Dumping by Dumping in a Cournot Model. In: Dynamics, Games and Science II, eds. Peixoto, M.M., Pinto, A.A., Rand, D.A., Springer Proceedings in Mathematics (2011)

2. DeVault, J.M.: Economics and the International Trade Commission. Southern Economic Journal 60, 463-78 (1993)

3. Dixit, A.K.: Anti-Dumping and Countervailing Duties Under Oligopoly. European Economic Review 32, 55-68 (1988)

4. Eaton, J., Grossman, G.M.: Optimal Trade and Industrial Policy for the US Automobile Industrial Policy Under Oligopoly. Quarterly Journal of Economics 100, 383-406 (1986)

5. Ethier, W.J., Fischer., R.D.: The New Protectionism. Journal of International Economic Integration 2 1-11 (1987)

6. Fischer, D.R.: Endogenous Probability of Protection and Firm Behavior. Journal of International Economics, 32, 149-63 (1992)

7. Hansen, L.W., Prusa, T.J.: Cumulation and ITC Decision Making: The Sum of the Parts is Greater than the Whole. Economic Enquiry 34, 746-69 (1996)

8. Hansen, L.W., Prusa, T.J.: The Economics and Politics of Trade Policy: An Empirical Analysis of ITC Decision Making. Review of International Economics 5, 230-45 (1997)

9. Moore, M.O.: Rules or Politics? An Empirical Analysis of ITC Antidumping Decisions. Economic Enquiry 30, 449-66 (1992)

10. Moore, M.O.: The Political Economy of Trade Protection. In: Krueger, ed. Anne O., University of Chicago Press (1996)

11. Reitzes, D.J.: Antidumping Policy. International Economic Review 34, 745-63 (1993)

12. Singh, N., Vives., X.: Price and Quantity Competition in a Differentiated Duopoly. Rand Journal of Economics 15, 546-554 (1984)

13. Staiger, R.W., Wolak., F.A.: The Effect of Domestic Antidumping Law in the Presence of Foreign Monopoly. Journal of International Economics 32, 265-87 (1992)

14. Viner, J.: Dumping: A Problem in International Trade. Chicago: University of Chicago Press (1923)

15. Vives., X.: Duopoly Information Equilibrium: Cournot and Bertrand. Journal of Economic Theory 34, 546-554 (1984) 